\title{
SLIDING MODE CONTROL FOR CURRENT LOOP IN AN INDUCTION MOTOR APPLIED TO A ROBOT ARM
}

\author{
Eber de C. Diniz, Antonio B.S. Júnior, Dalton A. Honório, Luiz H.S.C. Barreto, Laurinda L. N. dos Reis \\ Federal University of Ceará (UFC-DEE), Ceará - Brazil \\ lbarreto@dee.ufc.br, laurinda@ufc.br
}

\begin{abstract}
The control of a planar elbow manipulator driven by a squirrel-cage induction motor using sliding mode control (SMC) is presented in this paper. The modeling of the manipulator mechanical coupling as a load applied to the induction motor shaft is developed. This has direct influence on both $d q$ currents, which are chosen as the sliding manifold instead of controlling both mechanical and electrical parts as individual processes, like most industrial manipulators do. Conventional proportional-integral (PI) controllers are used for each loop, implying easy design procedure and implementation with low computational effort. The system can then be implemented by using a digital signal processor (DSP) and applied in industrial environments. Simulation and experimental results on a real manipulator are shown to validate the proposed control scheme. The results show that there is low steady-state error for the manipulator position.
\end{abstract}

Keywords - Sliding Mode Control, Induction Motor Drives, Manipulators, Digital Signal Processor, PI Controllers.

\section{INTRODUCTION}

Most of the robots use direct current (DC) or permanent magnet synchronous motors, making the manipulator's maintenance more expensive if compared to the induction motor counterparts, due to the relatively high cost of the rareearth magnets used in permanent magnet synchronous machines [1] or complexity of the DC motor. This is the main reason for replacing them for squirrel-cage induction motors whenever possible. In this case, Sliding Mode Control (SMC) becomes a nonlinear approach to control induction motors at high performance.

Since DC motors require maintenance more often than their AC counterparts, the adoption of induction motors is of great interest. However, many applications are dominated by DC drives and do not present good performance when using induction motor drives with constant volt/hertz $(v / f)$ scheme. In order to overcome such problem, vector control has been used for the last two decades in the control of AC motors [2] [3] [4] [5].

The complexity related to field orientation on manipulators comes from the plant modeling for application of adaptive control [6]. It is also concerns the nonlinear mechanical coupling between links [7], which is the specific

Manuscript received on 22/09/2011. Revised on $02 / 02 / 2012$ and on $25 / 08 / 2012$. Accepted for publication in $05 / 09 / 2012$ by recommendation for the Editor João Onofre Pereira Pinto. scope of this work. Hence to ensure good dynamic performance, various robust control strategies for induction motor drives have been reported in literature [8] [9]. One particular scheme has drawn special attention of researchers i.e. SMC, mainly due to simple design procedure, fast dynamic response, easy implementation, and good robustness in face of parameter variations and also load disturbances $[10][11]$, thus showing improved performance than the vector control scheme [12]. However, all of the aforementioned schemes have only been used to control a stand-alone induction motor.

The main complexity regarding the control of robot manipulators lies in determining the time history of joint inputs required to cause the end effector to execute a commanded motion. The joint inputs could be joint forces and torques, or they could be inputs to the actuators, as in the case of induction motors. Therefore, one must develop a control scheme able to compensate the mechanical coupling influence on joints and consider this in the control action. There are many applications that use induction motors nowadays e.g. elevators [13], robots [14][15][16], and mill drives 0 , where fast control over the torque and position of the motor are mandatory However, reports on manipulators with two or more degrees of freedom (DOF) using induction motors are basically restricted to simulation results only [5] [6] [8]. Within this context, this paper proposes the simplified control of an elbow planar manipulator using squirrel-cage induction motors by modeling the disturbance load and developing a SMC scheme for current tracking to compensate the mechanical coupling. For this purpose, the mechanical coupling has been determined for the specific case of the manipulator and then interpreted as a mechanical load at the induction motor shaft in the system modeling. A conventional PI controller was used for position and speed loop using modified Ziegler-Nichols method for tuning [18]. DSP TMS320F2812 is used in the experimental evaluation, thus enabling enhanced performance of the real-time algorithm and cost-effective design of intelligent controllers for induction motors. This implementation has also shown improved results if compared to the same case study using vector control in an induction motor drive [19]0.

\section{DYNAMIC MODELING OF THE INDUCTION MOTOR}

The block diagram of the indirect field-oriented induction motor drive is shown in Figure 1. The arrangement consists of an induction servo motor; a current ramp for comparison to drive the Space Vector Pulse Width Modulation (SVPWM) inverter, which has better performance than hysteresis based inverter [20]; a field orientation mechanism; a coordinate translator; an inner speed control loop; and an 
outer position control loop. The state equations of the induction motor in the synchronously rotating reference frame can be described by [21]:

$\frac{d}{d t}\left[\begin{array}{c}i_{d s} \\ i_{q s} \\ \lambda_{d r} \\ \lambda_{q r}\end{array}\right]=\left[\begin{array}{cccc}-\frac{R_{s}}{\sigma L_{s}}-\frac{R_{r}(1-\sigma)}{\sigma L_{r}} & \omega_{e} & \frac{L_{m} R_{r}}{\sigma L_{s} L_{r}{ }^{2}} & \frac{P \omega_{r} L_{m}}{2 \sigma L_{s} L_{r}{ }^{2}} \\ \omega_{e} & -\frac{R_{s}}{\sigma L_{s}}-\frac{R_{r}(1-\sigma)}{\sigma L_{r}} & \frac{-P \omega_{r} L_{m}}{2 \sigma L_{s} L_{r}{ }^{2}} & \frac{L_{m} R_{r}}{\sigma L_{s} L_{r}{ }^{2}} \\ \frac{L_{m} R_{r}}{L_{r}} & 0 & -\frac{R_{r}}{L_{r}} & \omega_{e}-\frac{P}{2} \omega_{r} \\ 0 & \frac{L_{m} R_{r}}{L_{r}} & -\left(\omega_{e}-\frac{P}{2} \omega_{r}\right) & -\frac{R_{r}}{L_{r}}\end{array}\right]\left[\begin{array}{l}i_{d s} \\ i_{q s} \\ \lambda_{d r} \\ \lambda_{q r}\end{array}\right](1)$ $+\frac{1}{\sigma L_{s}}\left[\begin{array}{l}v_{d s} \\ v_{q s} \\ 0 \\ 0\end{array}\right]$

$$
T_{e}=\frac{3 P}{4} \frac{L_{m}}{L_{r}}\left(i_{q s} \lambda_{d r}-i_{d s} \lambda_{q r}\right)
$$

Where:

$T_{e} \quad$ - electromagnetic torque;

$R_{s} \quad$ - stator resistance per phase;

$L_{s} \quad$ - stator magnetizing inductance per phase;

$R_{r} \quad$ - rotor resistance per phase referred to the stator;

$L_{r} \quad$ - rotor magnetizing inductance per phase referred to the stator;

$L_{m} \quad$ - magnetizing inductance per phase;

$P \quad$ - number of poles;

$\omega_{e} \quad$ - electrical angular speed;

$\omega_{r} \quad$ - slip angular speed;

$v_{d s}-d$-axis stator voltage;

$v_{q s}-q$-axis stator voltage;

$i_{d s} \quad-d$-axis stator current;

$i_{q s}-q$-axis stator current.

And,

$\sigma=1-\frac{L_{m}{ }^{2}}{L_{s} L_{r}} ; \quad \lambda_{q r}=L_{m} i_{q s}+L_{r} i_{d r} ; \quad \lambda_{d r}=L_{m} i_{d s}+L_{r} i_{q r}$.

In an ideal field-orientated induction motor, decoupling between $d$ and $q$-axis can be achieved, while the total rotor flux linkage is forced to align with the $d$-axis [2]. Accordingly, the flux linkage and its derivative in the $q$-axis are set to zero as:

$$
\lambda_{q r}=0 \text { and } \frac{d \lambda_{q r}}{d t}=0
$$

The rotor flux linkage can be found from the third row in (1) and by using (3) as:

$$
\lambda_{d r}=\frac{L_{m} i_{d s}}{1+s \frac{L_{r}}{R_{r}}}
$$

Compared with the time constant of the mechanical system, the time constant in (4) is assumed to be negligible and $i_{d s}$ is constant $\left(i_{d s}=i_{d s}^{*}\right)$ for the desired constant rated rotor flux. Then expression (4) becomes:

$$
\lambda_{d r}=L_{m} i_{d s}^{*}
$$

From (3) and (5), the torque (2) is simplified to:

$$
T_{e}=\frac{3 P}{4} \frac{L_{m}^{2}}{L_{r}} i_{d s}^{*} i_{q s}^{*},
$$

where $i_{q s}^{*}$ denotes the torque current command generated from the torque controller $G_{c}(s)$. When using indirect field orientation, the slip angular speed is necessary to calculate the unit vector for coordinate translation. By employing the fourth row of (1) and also (3), the slip angular frequency $\omega_{s l}$ can be estimated as:

$$
\omega_{s l}=\frac{L_{m} R_{r} i_{q s}^{*}}{L_{r} \lambda_{d r}}=\frac{R_{r} i_{q s}^{*}}{L_{r} i_{d s}^{*}}
$$

The generated torque, rotor speed $\omega_{r}$, and rotor angular position $\theta_{r}$ are related by:

$$
\omega_{r}=s \theta_{r}=\frac{1 / J}{s+B / J}\left[T_{e}(s)-T_{L}(s)\right]
$$

Where:

$$
\begin{array}{cl}
B & \text { - viscous damping frequency; } \\
J & \text { - inertia constant; } \\
T_{L} & \text { - load torque applied to the shaft. }
\end{array}
$$

The main problem when vector control algorithms are implemented in DSPs lies in the conversion of the current command represented in (5) and (6) into voltage command [2]. To accomplish this task, it is necessary to decouple the voltage equation enabling independent control of the two stator current components in $d q 0$ frame [3].

This procedure is detailed in [6], giving:

$$
\begin{gathered}
v_{q s}^{e}=\left(r_{s}+L_{s}^{\prime} s\right) i_{q s}^{e}+\omega_{e} L_{s} i_{d s}^{e} \\
v_{d s}^{e}=r_{s} i_{d s}^{e}-\omega_{e} L_{s}^{\prime} i_{q s}^{e}
\end{gathered}
$$




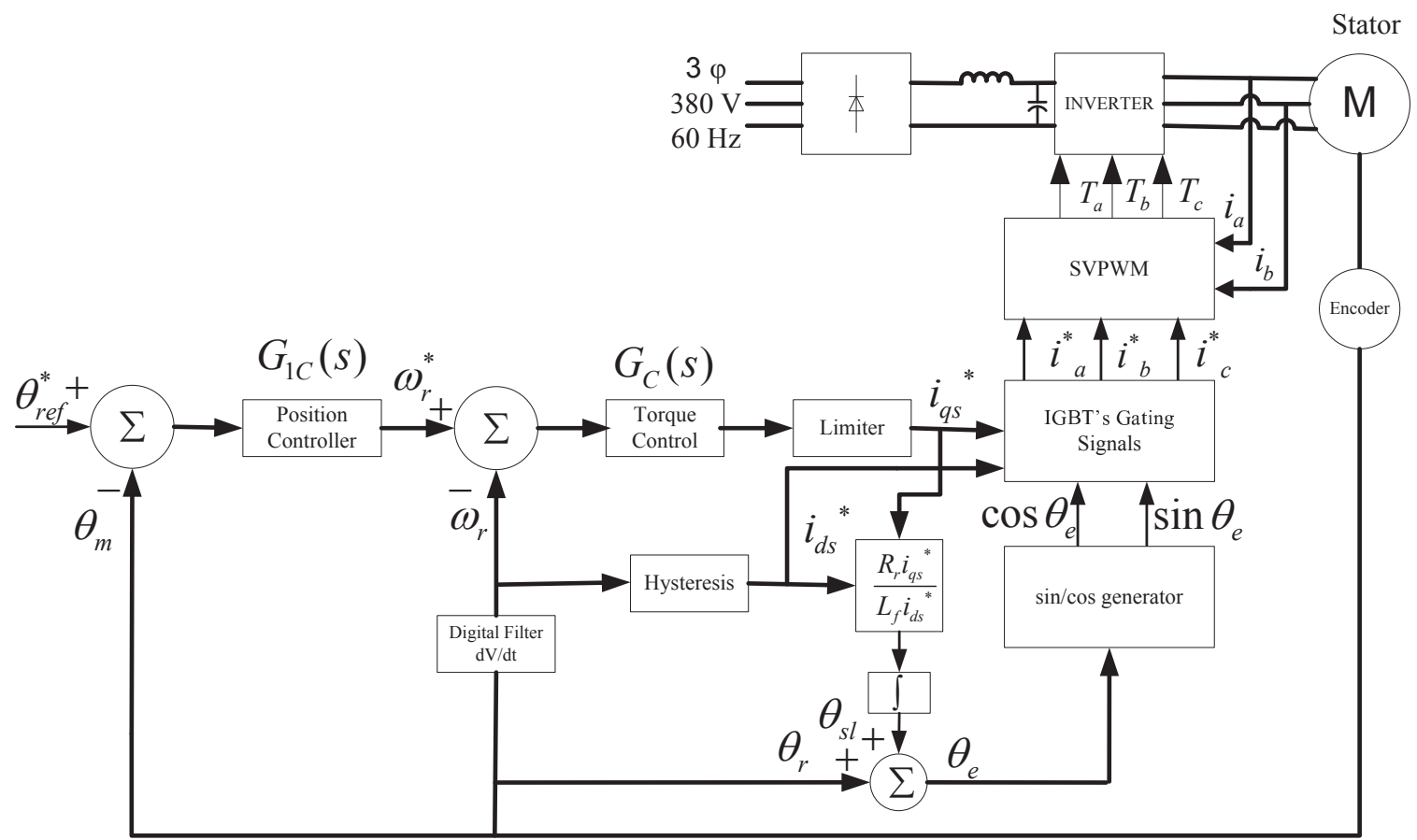

Fig. 1. Block diagram representing field-oriented induction motor drive.

Where:

$$
L_{s}^{\prime}=L_{s}-\frac{L_{m}^{2}}{L_{r}},
$$

while the superscript index " $e$ " refers to the electrical reference.

\section{MODELING THE NONLINEAR MECHANICAL COUPLING AS A DISTURBANCE}

For applications that do not involve very fast motion, especially in robots with large gear reduction among the actuators and the links, the independent position control for each joint works satisfactorily.

For the following discussion, let us assume for simplicity that:

where:

$$
q_{k}=\theta_{s k}=r \theta_{m k},
$$

$\theta_{s k}$ - shaft angular position.

$r \theta_{m k}$ - link angular position with $r$ being the gear ratio.

Then the motion equations for the manipulator, known as Euler-Lagrange Equations, can be written as [7]:

$$
\sum_{j=1}^{n} d_{k j}(q) \ddot{q}_{j}+\sum_{i, j=1}^{n} c_{i k j}(q) \dot{q}_{i} \dot{q}_{j}+g_{k}(q)=\tau_{k}, k=1, \ldots, n
$$

Where $\tau_{k}$ is the torque for link $k$. Equation (13) represents nonlinear inertial, centripetal, Coriolis, and gravitational coupling effects due to the motion of the manipulator. For the manipulator shown in Figure 2, only the second and third joints are of interest, represented by systems $O_{1} X_{1} Y_{1} Z_{1}$ and $O_{2} X_{2} Y_{2} Z_{2}$ respectively, because the first one is not affected by coupling effects [7].

For a situation where the generalized coordinates are not the joint variables, one must consider a different calculation for the Lagrangian equations [7]. In the case of the proposed study, one must choose the generalized coordinates as shown in Figure 3 because angle $\theta_{2}$ is determined by driving the motor of the second DOF, which is not affected by angle $\theta_{l}$.

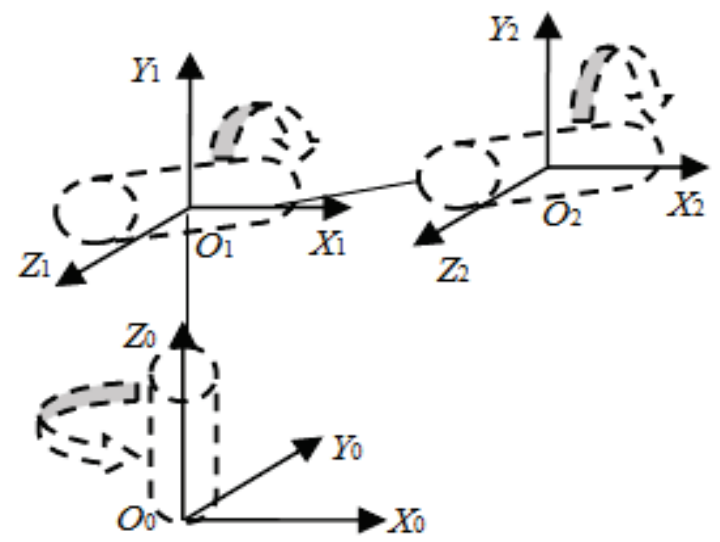

Fig. 2. 3-DOF manipulator driven by squirrel-cage induction motors.

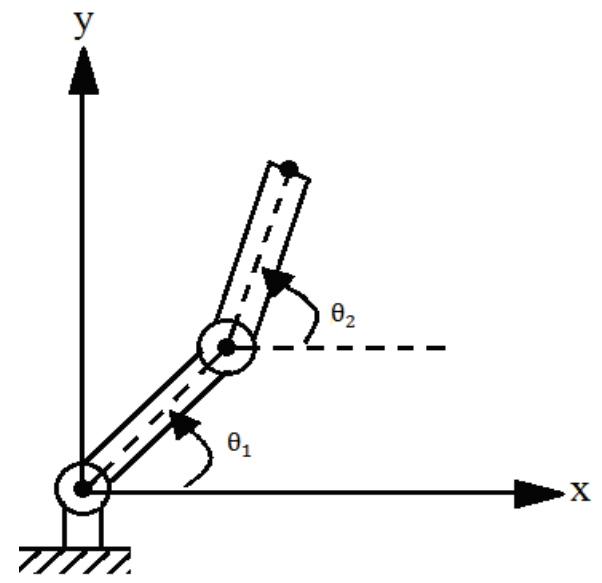

Fig. 3. Generalized coordinates for the robot represented in Fig. 2. 
The dynamical equations for this configuration, according to Figure 3, show that some simplifications are necessary. The following expression then results [7]:

$v_{c 1}=\left[\begin{array}{cc}-\mathrm{l}_{\mathrm{c} 1} \sin \theta_{1} & 0 \\ \mathrm{l}_{\mathrm{c} 1} \cos \theta_{1} & 0 \\ 0 & 0\end{array}\right]\left[\begin{array}{l}\dot{\theta}_{1} \\ \dot{\theta}_{2}\end{array}\right]$,

$v_{c 2}=\left[\begin{array}{cc}\mathrm{l}_{1} \sin \theta_{1} & -\mathrm{l}_{\mathrm{c} 2} \sin \theta_{2} \\ \mathrm{l}_{1} \cos \theta_{1} & \mathrm{l}_{\mathrm{c} 2} \cos \theta_{2} \\ 0 & 0\end{array}\right]\left[\begin{array}{l}\dot{\theta}_{1} \\ \dot{\theta}_{2}\end{array}\right]$

Where:

$l_{c n}$ - center of mass for link $n$.

$l_{n} \quad$ - link size.

$k \quad$ - unit vector in $z$ direction.

$v_{c i}$ - center of mass speed for link $i$.

The inertial matrix $D(\theta)$ is given by:

$$
\mathbf{D}(\theta)=\left[\begin{array}{cc}
\mathrm{m}_{1} \mathrm{l}_{\mathrm{c} 1}{ }^{2}+\mathrm{m}_{2} \mathrm{l}_{1}{ }^{2}+\mathrm{m}_{1} \mathrm{l}_{\mathrm{c} 1} & \mathrm{~m}_{2} \mathrm{l}_{1} \mathrm{l}_{\mathrm{c} 2} \cos \left(\theta_{2}-\theta_{1}\right) \\
\mathrm{m}_{2} \mathrm{l}_{1} \mathrm{l}_{\mathrm{c} 2} \cos \left(\theta_{2}-\theta_{1}\right) & \mathrm{m}_{2} \mathrm{l}_{\mathrm{c} 2}{ }^{2}+\mathrm{m}_{2} \mathrm{l}_{\mathrm{c} 2}
\end{array}\right]
$$

While the Christoffel symbols are defined by [7]:

$$
c_{i j k}=\frac{1}{2}\left\{\frac{\partial d_{j k}}{\partial q_{i}}+\frac{\partial d_{k i}}{\partial q_{i}}-\frac{\partial d_{i j}}{\partial q_{k}}\right\}
$$

From expression (16) and considering only the last two DOFs, six coefficients can be obtained:

$$
\begin{gathered}
c_{111}=\frac{1}{2} \frac{\partial d_{11}}{\partial \theta_{1}}=0 \\
c_{121}=c_{211}=\frac{1}{2} \frac{\partial d_{11}}{\partial \theta_{2}}=0 \\
c_{221}=\frac{\partial d_{12}}{\partial \theta_{2}}-\frac{1}{2} \frac{\partial d_{22}}{\partial \theta_{1}}=-\mathrm{m}_{2} \mathrm{l}_{1} \mathrm{l}_{\mathrm{c} 2} \sin \left(\theta_{2}-\theta_{1}\right) \\
c_{112}=\frac{\partial d_{21}}{\partial \theta_{1}}-\frac{1}{2} \frac{\partial d_{11}}{\partial \theta_{2}}=\mathrm{m}_{2} \mathrm{l}_{1} \mathrm{l}_{\mathrm{c} 2} \sin \left(\theta_{2}-\theta_{1}\right) \\
c_{212}=c_{122}=\frac{1}{2} \frac{\partial d_{22}}{\partial \theta_{1}}=0 \\
c_{222}=\frac{1}{2} \frac{\partial d_{22}}{\partial \theta_{2}}=0
\end{gathered}
$$

$$
P=\mathrm{m}_{1} \mathrm{gl}_{\mathrm{c} 1} \sin \theta_{1}+\mathrm{m}_{2} \mathrm{~g}\left(\mathrm{l}_{1} \sin \theta_{1}+\mathrm{l}_{\mathrm{c} 2} \sin \theta_{2}\right),
$$

and the gravitational forces are:

$$
\begin{gathered}
g_{1}=\left(\mathrm{m}_{1} \mathrm{l}_{\mathrm{c} 1}+\mathrm{m}_{2} \mathrm{l}_{1}\right) g \cos \theta_{1} \\
g_{2}=\mathrm{m}_{2} \mathrm{l}_{\mathrm{c} 2} g \cos \theta_{2}
\end{gathered}
$$

Finally, the dynamic equations are:

$$
\begin{aligned}
& \mathrm{d}_{11} \ddot{\theta_{1}}+\mathrm{d}_{12} \ddot{\theta_{2}}+\mathrm{c}_{221} \dot{\theta}_{2}^{2}+g_{1}=\tau_{\mathrm{L} 1} \\
& \mathrm{~d}_{21} \ddot{\theta}_{1}+\mathrm{d}_{22} \ddot{\theta}_{2}+\mathrm{c}_{112} \dot{\theta}_{1}^{2}+g_{2}=\tau_{\mathrm{L} 2}
\end{aligned}
$$

\section{SLIDING MODE CURRENT CONTROL DESIGN}

The main difficulty in the control of induction motor drives comes from the multiplicative nonlinearity of the developed electromagnetic torque. However, if the current control problem is overcome, speed and position regulation can be easily achieved by outer-loop controllers. For this purpose, the SMC scheme is first applied to the inner-loop current control.

From the SMC point of view, the system trajectories must be required to approach the specified manifold form to any initial state in the state plane. Then the system behavior is governed by the dynamics of the manifold in which the system trajectories remain. Using a proportional controller for position control and a PI one for speed control [10], which are represented in Figure 4, the reference electromagnetic torque can be described by:

$$
\omega_{r}^{*}(t)=K_{p 1}\left[\theta_{\text {ref }}(t)-\theta_{m}(t)\right]
$$

$$
\begin{aligned}
& \dot{T}_{e}^{*}=K_{p 2}\left(\dot{\omega}_{r}^{*}-\dot{\omega}_{r}\right)+K_{i 2}\left(\omega_{r}^{*}-\omega_{r}\right)=\frac{P K_{p 2} k_{T}}{J} i_{q s} T_{L} \lambda_{d r} \\
& -\left(\frac{K_{p 2} K_{p 1}}{P}+K_{i 2}\right) \omega_{r}-K_{p 1} K_{i 2} \theta_{m}+\frac{P K_{p 2}}{J} T_{L} \\
& +K_{p 1} K_{p 2} \theta_{r e f}+K_{p 1} K_{i 2} \theta_{r e f}
\end{aligned}
$$

Where:

$$
k_{T}=\frac{3 P}{4} \frac{L_{m}}{L_{r}}
$$

The potential energy of the manipulator $P$ in terms of $\theta_{1}$ and $\theta_{2}$ is:

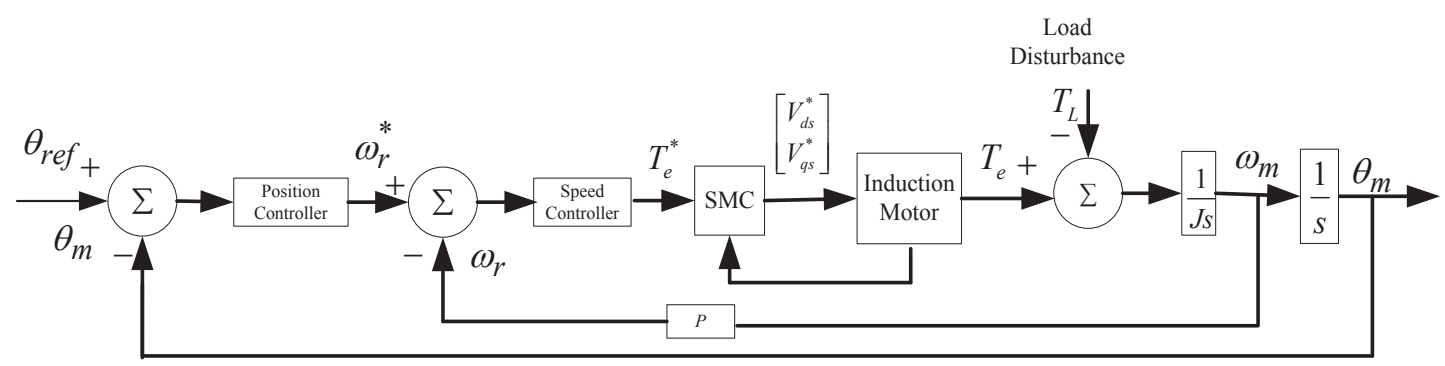

Fig. 4. Single induction motor position drive using SMC. 


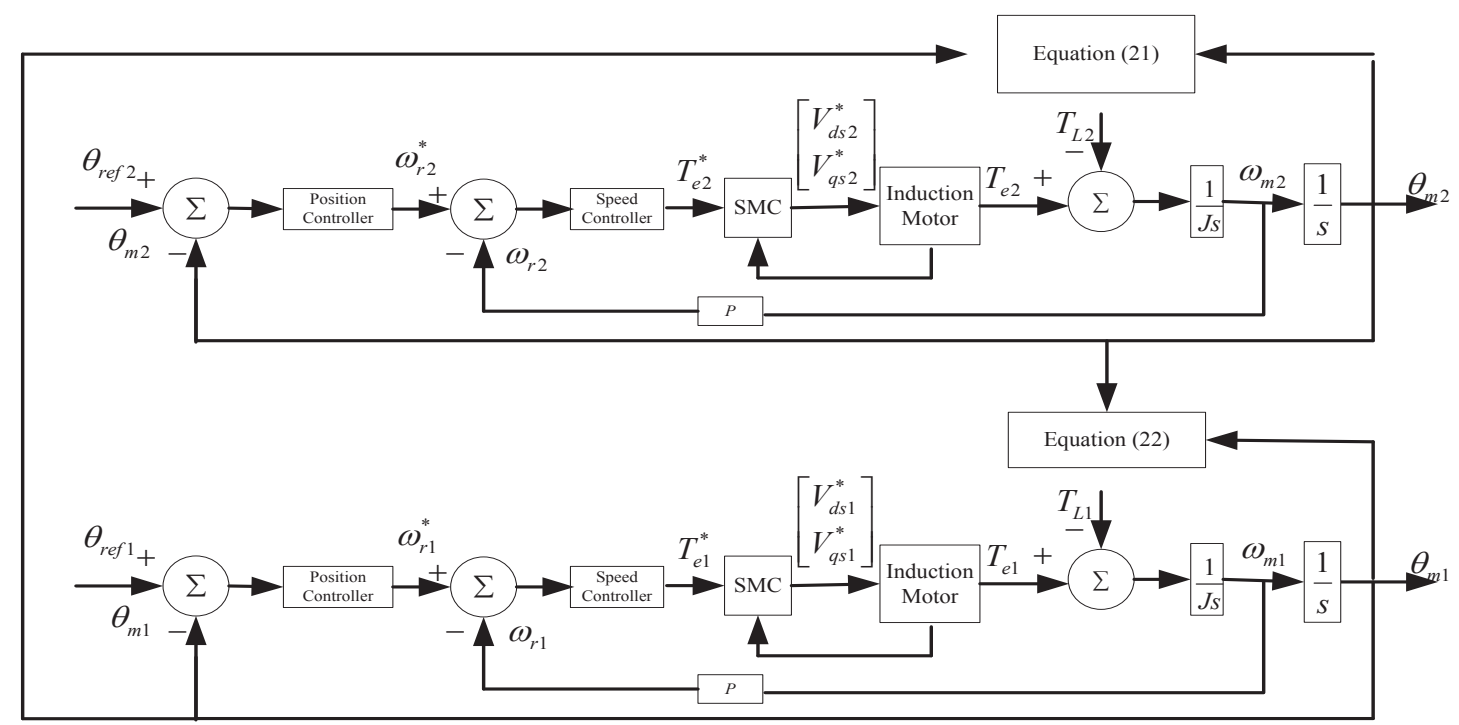

Fig. 5. 2-DOF manipulator with induction motor position drive using SMC.

The load torque given in (24) can be replaced by the dynamic equations of both links for joint control i.e. (21) and (22). Also, by using (1) and (7), a twelfth-order state variable dynamic equation for the whole system can be obtained, as seen in Figure 5.

The torque command is influenced by both quadrature and direct stator currents, according to (4) and (9). It is then reasonable to adopt such currents as the sliding manifold for the proposed study. The switching function vector for the 2DOF robot is defined as:

$$
s=\left[\begin{array}{l}
s_{1} \\
s_{2} \\
s_{3} \\
s_{4}
\end{array}\right]=\left[\begin{array}{l}
i_{d s 1}-i_{d s 1}^{*} \\
i_{q s 1}-i_{q s 1}^{*} \\
i_{d s 2}-i_{d s 2}^{*} \\
i_{q s 2}-i_{q s 2}^{*}
\end{array}\right]
$$

From [7], it can be established that the sliding manifold $s=0$ is globally attractive and an invariant set. The symbol "** denotes the reference signal, while $i_{d s i}$ is the direct current of the $i$-th DOF and $i_{q s i}$ is the quadrature current of the $i$-th DOF in $d q 0$ reference frame. Keeping the rotoric flux at a constant rate, and using equations (5) and (9), the reference signals are given by:

$$
\left[\begin{array}{c}
i_{d s 1}^{*} \\
i_{q s 1}^{*} \\
i_{d s 2}^{*} \\
i_{q s 2}^{*}
\end{array}\right]=\left[\begin{array}{l}
\frac{\lambda_{d r 1}}{L_{m 1}} \\
\frac{T_{e 1}^{*}}{k_{T 1} \lambda_{d r 1}} \\
\frac{\lambda_{d r 2}}{L_{m 2}} \\
\frac{T_{e 2}^{*}}{k_{T 2} \lambda_{d r 2}}
\end{array}\right]
$$

By using expressions (1), (21), (22), (24), (26), and (27), it gives:

$$
\begin{aligned}
& \dot{s}=\left[\begin{array}{l}
a_{11} \\
a_{21} \\
a_{12} \\
a_{22}
\end{array}\right]+\left[\begin{array}{cc}
0 & 0 \\
b_{11} & 0 \\
0 & 0 \\
0 & b_{12}
\end{array}\right]\left[\begin{array}{c}
\tau_{L 1} \\
\tau_{L 2}
\end{array}\right]+\left[\begin{array}{cc}
0 & 0 \\
b_{21} & 0 \\
0 & 0 \\
0 & b_{22}
\end{array}\right]\left[\begin{array}{l}
\dot{\theta}_{r e f 1} \\
\dot{\theta}_{r e f 2}
\end{array}\right]+\left[\begin{array}{cc}
0 & 0 \\
b_{31} & 0 \\
0 & 0 \\
0 & b_{32}
\end{array}\right]\left[\begin{array}{l}
\theta_{r e f 1} \\
\theta_{r e f 2}
\end{array}\right] \\
& +\frac{1}{\sigma L_{s}}\left[\begin{array}{l}
v_{d s 1} \\
v_{q s 1} \\
v_{d s 2} \\
v_{q s 2}
\end{array}\right]
\end{aligned}
$$

Where:

$$
\begin{aligned}
& a_{1 i}=-\frac{1}{\sigma L_{s i}}\left(R_{s i}+\frac{L_{m i}^{2}}{\tau_{r i} L_{r i}}\right) i_{d s i}+\frac{L_{m i}}{\tau_{r i} i} \frac{i_{q s i}^{2}}{\lambda_{d r i} i}+\omega_{r i} i_{q s i}+\frac{L_{m i}}{\tau_{r i} L_{\sigma i} L_{r i}} \lambda_{d r i}, \\
& a_{2 i}=-\frac{1}{\sigma L_{s i}}\left(R_{s i}+\frac{L_{m i}^{2}}{\tau_{r i} L_{r i}}\right) i_{q s i}-\frac{L_{m i}}{\tau_{r i}} \frac{i_{q s i} i_{d s i}}{\lambda_{d r i}}+\omega_{r i} i_{d s i} \\
& +\frac{L_{m i}}{\sigma L_{s i} L_{r i}} \lambda_{d r i} \omega_{r i}-\frac{1}{k_{T i} \lambda_{d r i}}\left(\frac{P_{i} K_{p i 2} k_{T i}}{J_{i}} i_{q s i} T_{L i} \lambda_{d r i}\right. \\
& \left.-\left(\frac{K_{p i 2} K_{p i 1}}{P_{i} / 2}+K_{i i 2}\right) \omega_{r}-K_{p i 1} K_{i i 2} \theta_{i}\right), \\
& b_{1 i}=\frac{P_{i} / 2 K_{p i 2}}{k_{r i} \lambda_{d r i} J_{i}}, \quad b_{2 i}=-\frac{K_{p i 2} K_{p i 1}}{k_{T i} \lambda_{d r i}}, \quad \text { and } \quad b_{3 i}=-\frac{K_{p i 1} K_{i i 2}}{k_{T i} \lambda_{d r i}}
\end{aligned}
$$

Based on Gao's reaching law design method [22], a control law for the inner-loop sliding-mode current tracking is proposed as follows:

$$
\left[\begin{array}{l}
v_{d s 1} \\
v_{q s 1} \\
v_{d s 2} \\
v_{q s 2}
\end{array}\right]=-\sigma L_{s}\left(\begin{array}{l}
{\left[\begin{array}{l}
\hat{a}_{11} \\
\hat{a}_{21} \\
\hat{a}_{12} \\
\hat{a}_{22}
\end{array}\right]+\left[\begin{array}{cc}
0 & 0 \\
b_{21} & 0 \\
0 & 0 \\
0 & b_{22}
\end{array}\right]\left[\begin{array}{l}
\dot{\theta}_{r e f 1} \\
\dot{\theta}_{r e f 2}
\end{array}\right]+\left[\begin{array}{cc}
0 & 0 \\
b_{31} & 0 \\
0 & 0 \\
0 & b_{32}
\end{array}\right]\left[\begin{array}{l}
\theta_{r e f 1} \\
\theta_{r e f 2}
\end{array}\right]+} \\
\left.\left[\begin{array}{cccc}
q_{1} & 0 & 0 & 0 \\
0 & q_{2}+L_{1} & 0 & 0 \\
0 & 0 & q_{3} & 0 \\
0 & 0 & 0 & q_{4}+L_{2}
\end{array}\right] \operatorname{sgn}(s)+\left[\begin{array}{cccc}
k_{1} & 0 & 0 & 0 \\
0 & k_{2} & 0 & 0 \\
0 & 0 & k_{3} & 0 \\
0 & 0 & 0 & k_{4}
\end{array}\right] s\right)
\end{array}\right.
$$


where:

$$
\begin{aligned}
& \mathrm{L}_{1}=\left|\mathrm{b}_{11}\left(\mathrm{~d}_{11} \ddot{\theta}_{\max 1}+\mathrm{d}_{12} \ddot{\theta}_{\max 2}+\mathrm{c}_{221} \dot{\theta}_{\max 2}^{2}+g_{1}\right)\right| \\
& \mathrm{L}_{2}=\left|\mathrm{b}_{12}\left(\mathrm{~d}_{21} \ddot{\theta}_{\max 1}+\mathrm{d}_{22} \ddot{\theta}_{\max 2}+\mathrm{c}_{112} \dot{\theta}_{\max 2}^{2}+g_{1}\right)\right|
\end{aligned}
$$

$\hat{a}_{i j}$ denotes the estimation of $a_{i j}$ and $q_{1}>\left|\hat{a}_{11}-a_{11}\right|$, $q_{2}>\left|\hat{a}_{21}-a_{21}\right|, q_{3}>\left|\hat{a}_{12}-a_{12}\right|, q_{4}>\left|\hat{a}_{22}-a_{22}\right|, k_{1}>0$, $k_{2}>0, k_{3}>0, k_{4}>0, \ddot{\theta}_{\text {maxi }}$ and $\dot{\theta}_{\text {maxi }}^{2}$ are the restrictions for joint acceleration and speed, respectively. With this control law, the sliding manifold $s=0$ is satisfied. It is important to notice that the derivation of $L_{1}$ and $L_{2}$ comes directly from equations (21) and (22). It ensures that the dynamic behavior of manipulator's torque in each DOF influences the calculation of current commands in the control law stated by equation (30).

The proof of the aforementioned statement is given as follows. Let us consider a scalar Lyapunov function candidate as:

$$
V(s)=\frac{1}{2} s^{T} s=\frac{1}{2}\left(s_{1}^{2}+s_{2}^{2}+s_{3}^{2}+s_{4}^{2}\right)
$$

The derivative of $V(s)$ with the system trajectories based on (33) is given by:

$$
\begin{aligned}
& \quad \dot{V}(s)=s_{1}\left(\mathrm{a}_{11}-\hat{\mathrm{a}}_{11}\right)-s_{1} q_{1} \operatorname{sgn}\left(s_{1}\right)-k_{1} s_{1}^{2}+ \\
& s_{2}\left(\mathrm{a}_{21}-\hat{\mathrm{a}}_{21}\right)-s_{2} b_{11} T_{L 1}-s_{2}\left[\left(q_{2}-L_{1}\right) \operatorname{sgn}\left(s_{2}\right)-k_{2} s_{2}^{2}+\right. \\
& s_{3}\left(\mathrm{a}_{12}-\hat{\mathrm{a}}_{12}\right)-s_{3} q_{3} \operatorname{sgn}\left(s_{3}\right)-k_{3} s_{3}^{2}+s_{4}\left(\mathrm{a}_{22}-\hat{\mathrm{a}}_{22}\right)- \\
& s_{4} b_{21} T_{L 2}-s_{4}\left[\left(q_{4}-L_{2}\right) \operatorname{sgn}\left(s_{4}\right)-k_{4} s_{4}^{2} \leq\left|s_{1}\right|\left|\mathrm{a}_{11}-\hat{\mathrm{a}}_{11}\right|-\right. \\
& \left|s_{1}\right| q_{1}-k_{1} s_{1}^{2}+\left|s_{2}\right|\left|\mathrm{a}_{21}-\hat{\mathrm{a}}_{21}\right|-\left|s_{2}\right| q_{2}-k_{2} s_{2}^{2}+ \\
& \left|s_{3}\right|\left|\mathrm{a}_{12}-\hat{\mathrm{a}}_{12}\right|-\left|s_{3}\right| q_{3}-k_{3} s_{3}^{2}+\left|s_{4}\right|\left|\mathrm{a}_{22}-\hat{\mathrm{a}}_{22}\right|-\left|s_{4}\right| q_{4}- \\
& k_{4} s_{4}^{2}=-\left|s_{1}\right|\left(q_{1}-\left|\mathrm{a}_{11}-\hat{\mathrm{a}}_{11}\right|\right)-\left|s_{2}\right|\left(q_{2}-\mid \mathrm{a}_{12}-\right. \\
& \left.\hat{\mathrm{a}}_{12} \mid\right)-\left|s_{3}\right|\left(q_{3}-\left|\mathrm{a}_{21}-\hat{\mathrm{a}}_{21}\right|\right)-\left|s_{4}\right|\left(q_{4}-\left|\mathrm{a}_{22}-\hat{\mathrm{a}}_{22}\right|\right)- \\
& \left(k_{1} s_{1}^{2}+k_{2} s_{2}^{2}+k_{3} s_{3}^{2}+k_{4} s_{4}^{2}\right)
\end{aligned}
$$

For the aforementioned conditions, a negative derivative results. Therefore the system trajectories are guaranteed to approach the sliding manifold from any initial state in the state plan [22]. When the system is far from the sliding manifold, this inequality shows that $\dot{V}(s)$ is dominated by $-\left(k_{1} s_{1}^{2}+k_{2} s_{2}^{2}+k_{3} s_{3}^{2}+k_{4} s_{4}^{2}\right)$, because $s_{i}^{2}$ represents the difference between currents, and therefore increments in $k_{i}$ values cause the reaching time to be reduced. On the other hand, $\quad \dot{V}(s)$ is by $-\left|s_{1}\right|\left(q_{1}-\left|\mathrm{a}_{11}-\hat{\mathrm{a}}_{11}\right|\right)-\left|s_{2}\right|\left(q_{2}-\left|\mathrm{a}_{12}-\hat{\mathrm{a}}_{12}\right|\right)-\left|s_{3}\right|\left(q_{3}-\right.$ $\left.\left|\mathrm{a}_{21}-\hat{\mathrm{a}}_{21}\right|\right)-\left|s_{4}\right|\left(q_{4}-\left|\mathrm{a}_{22}-\hat{\mathrm{a}}_{22}\right|\right)$ when the current trajectories are close to the sliding manifold, and small values of $\left(q_{\mathrm{i}}-\left|\mathrm{a}_{\mathrm{ij}}-\hat{\mathrm{a}}_{i j}\right|\right)$ reduce the chattering. As $a_{i j}$ and $\hat{a}_{i j}$ are defined by system parameters and their values do not differ so much from each other, chattering is basically only driven by $q_{\mathrm{i}}$ values.

\section{SIMULATION AND EXPERIMENTAL RESULTS}

\section{A. Simulation Results}

The induction servo motor used in the drive system is a three-phase delta-connected, squirrel-cage machine, whose parameters are given in Table I. The manipulator parameters are shown in Table II.
TABLE I

Motor parameters

\begin{tabular}{cc}
\hline Parameters & Value \\
\hline Rated power & $0.25 \mathrm{HP}$ \\
\hline Rated speed & $1725 \mathrm{rpm}$ \\
\hline Rated voltage & $220 \mathrm{~V}$ \\
\hline Rated current & $1.26 \mathrm{~A}$ \\
\hline Number of poles & 4 \\
\hline $\begin{array}{c}\text { Rotor resistance } \\
\text { referred to the stator }\end{array}$ & $87.44 \Omega$ \\
\hline Stator resistance & $35.58 \Omega$ \\
\hline $\begin{array}{c}\text { Rotor inductance } \\
\text { referred to the stator }\end{array}$ & $0.16 \mathrm{H}$ \\
\hline Stator inductance & $0.16 \mathrm{H}$ \\
\hline Mutual inductance & $0.884 \mathrm{H}$ \\
\hline Inertia moment & $5 \cdot 10^{-4} \mathrm{~kg} \cdot \mathrm{m}^{2}$ \\
\hline Viscous friction \\
coefficient
\end{tabular}

TABLE II

Manipulator parameters

\begin{tabular}{cc} 
Parameters & Value \\
\hline Link II mass & $12.45 \mathrm{~kg}$ \\
\hline Link II size & $53 \mathrm{~cm}$ \\
\hline $\begin{array}{c}\text { Link II distance from } \\
\text { Center of mass }\end{array}$ & $14.9 \mathrm{~cm}$ \\
\hline $\begin{array}{c}\text { Link II moment of } \\
\text { inertia }\end{array}$ & $0.43 \mathrm{~kg} \cdot \mathrm{m}^{2}$ \\
\hline Link II rotation angle & $225^{\circ}$ \\
\hline Link III mass & $5.5 \mathrm{~kg}$ \\
\hline Link III size & $37.5 \mathrm{~cm}$ \\
\hline $\begin{array}{c}\text { Link III distance from } \\
\text { center of mass }\end{array}$ & $10.6 \mathrm{~cm}$ \\
\hline $\begin{array}{c}\text { Link III moment of } \\
\text { inertia }\end{array}$ & $0.28 \mathrm{~kg} \cdot \mathrm{m}^{2}$ \\
\hline Link III rotation angle & $300^{\circ}$ \\
\hline
\end{tabular}

The criterion chosen for speed and position loops lies in the design of PI controllers for which the system does not present critical damping characteristic. The point on Nyquist curve defined by $(2.47,-130)$ for speed loop was reallocated at $(0,-128.5)$ to match this requirement and was obtained in [19]. Using the same rule for the position loop, the point is moved from $(-131,-1880)$ to $(-135.2,-198)$. The simulation results for the link position control can be seen in Figures 6 and 7.

In the SMC scheme, the main goal of the proposed controller is fast settling time instead of reduced chattering. The values used for the SMC algorithm are: $k_{1}=8500$, $k_{2}=5500, k_{3}=4500, k_{4}=1500$, and $q_{1}=q_{2}=q_{3}=q_{4}=300$. For the position proportional controller and speed PI controller, the calculated parameters observing the desired Nyquist points mentioned in [19] are $K_{p 11}=10.3, K_{p 21}=15.5, K_{i 21}=5.7$ and $K_{p 12}=7.3, K_{p 22}=40.3, K_{i 22}=40.0$.

From Figures 6 and 7, it can be observed that the position control is more difficult to be achieved at some positions, mainly because the second DOF has a higher load coupled to its link if compared to the third DOF, also considering that they are driven by motors rated at same power. Also, the mechanical coupling becomes evident. When the position of the $2^{\text {nd }}$ DOF changes, it has small influence in the mechanical torque of the $3^{\text {rd }} \mathrm{DOF}$, and vice-versa, as stated by equations (21) and (22) and seen in Figures 6 and 7. This can be compensated using the calculated control law stated 
by equation (30), which considers the mechanical coupling as one of its terms $\left(L_{1}\right.$ and $L_{2}$, obtained from equations (31) and (32), respectively). An error of $0.7 \%$ in position command is obtained in steady state for the second DOF, while $0.15 \%$ results for the third DOF. The responses for the current errors are shown in Figures 8 to 11 considering the parameters adopted for the SMC scheme. It can be seen that SMC performance is satisfactory, as the current errors, which constitute the system hyperplane, are around the sliding manifold $s=0$.

Position(radians)

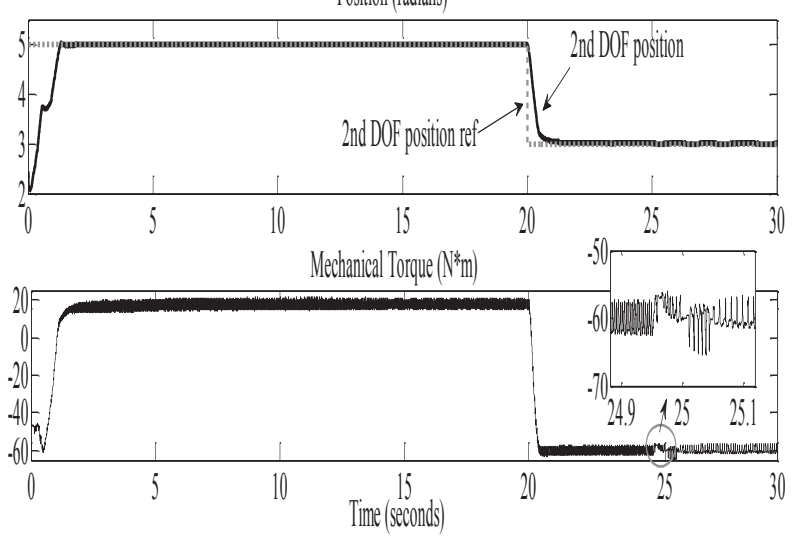

Fig. 6. Simulation results of position control and mechanical torque for the $2^{\text {nd }} \mathrm{DOF}$.

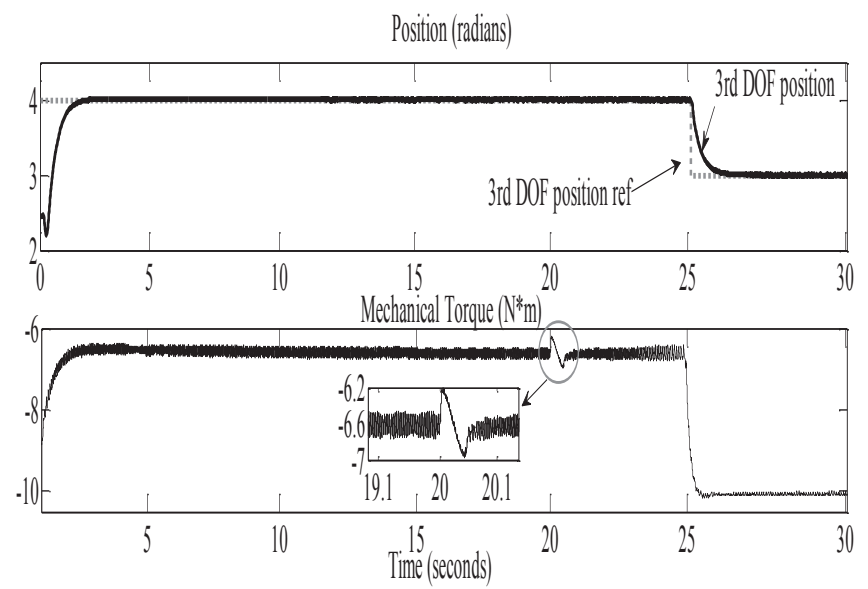

Fig. 7. Simulation results of position and the mechanical torque for the $3^{\text {rd }}$ DOF.

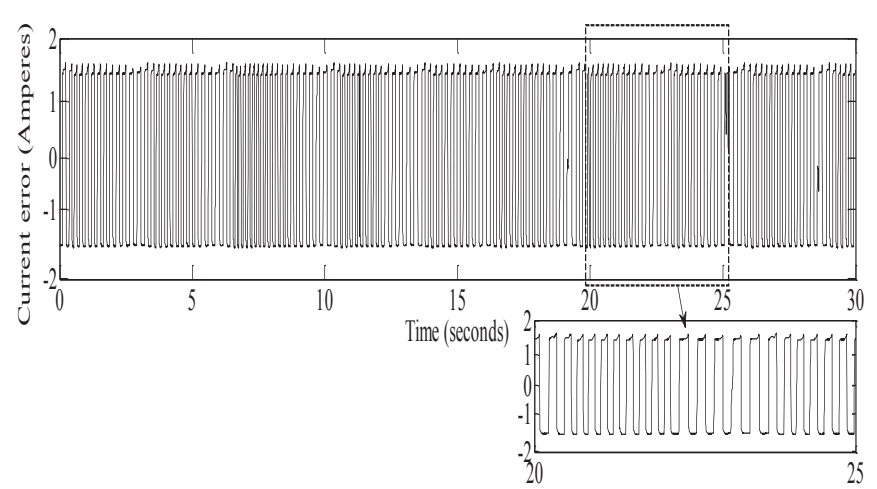

Fig. 8. Simulation results of induction motor quadrature error current for the $2^{\text {nd }} \mathrm{DOF}$.

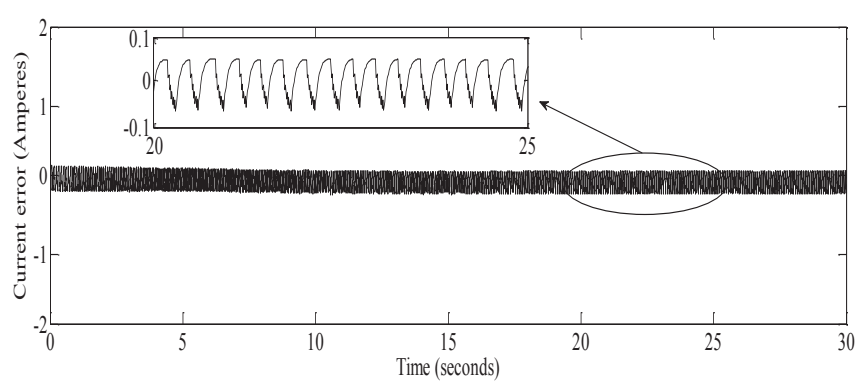

Fig. 9. Simulation results of induction motor direct current error for the $2^{\text {nd }} \mathrm{DOF}$.

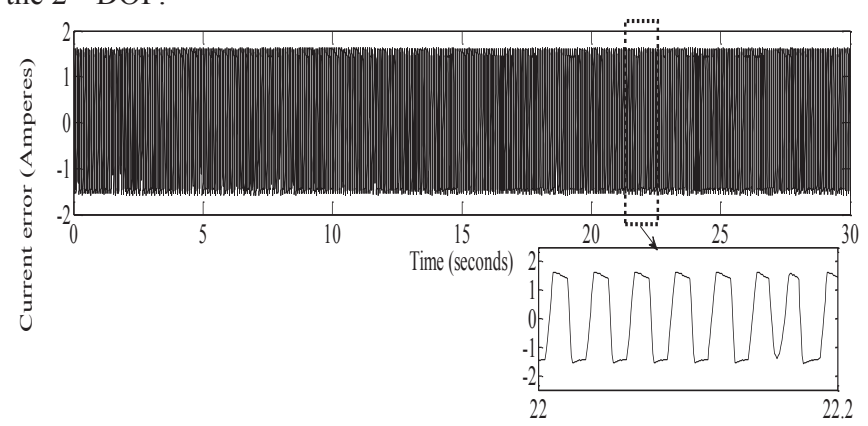

Fig. 10. Simulation results of induction motor quadrature current error for $3^{\text {rd }}$ DOF.

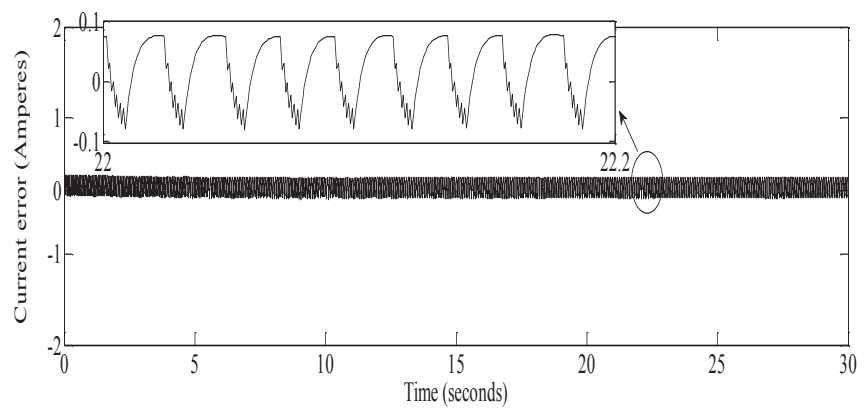

Fig.11. Simulation results of induction motor direct current error for the $3^{\text {rd }}$ DOF.

\section{B. Experimental Results}

Experimental results on the elbow planar manipulator shown in Figure 12 are presented, thus validating simulation results, which give a low error at steady-state for manipulator position.

The SMC algorithm was implemented on a DSP TMS320F2812 from Texas Instruments ${ }^{\circledR}$ with sample frequency of $2.5 \mathrm{kHz}$. A DC-AC converter with bootstrap was implemented using SVPWM, with switching frequency of $7.5 \mathrm{kHz}$. The drive signals for the converter switches are obtained from the DSP. Data was acquired using NI USB6009 Data Acquisition ${ }^{\circledR}$ from National ${ }^{\circledR}$, and later plotted using Scilab ${ }^{\circledR}$. Figures 13 and 16 show the link's angular position for the second and third DOFs, respectively. The steady-state errors obtained for position control are $1.3 \%$ and $0.6 \%$, being lower than those obtained with vector control algorithm applied to the same manipulator $(2.1 \%$ and $1.1 \%$, respectively [19]), as more robust position tracking results in this case. 


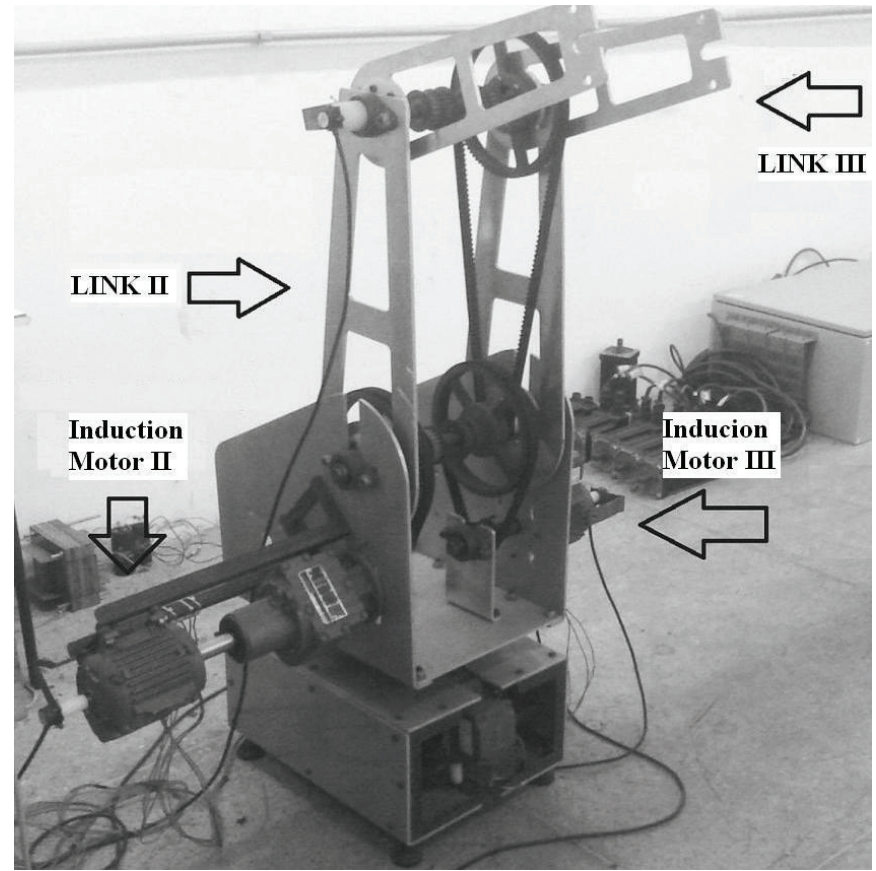

Fig. 12. Three-link manipulator driven by induction motors.

The q-axis current errors, which are part of the sliding manifold described in equation (26) and represent the machine torque variation, are shown in Figures 14 and 17. It is worth to mention that, for the second DOF, the induction motor must drive a reductor and also has the highest load considering all the involved DOFs, consequently leading to high power levels. This can be clearly seen in Figure 14, where the quadrature current, which represents the machine torque according to equation (6), is higher for the second link. As the third link has almost no load, the induction motor quadrature current for this DOF is lower than the second DOF counterpart, as seen in Figure 17. Then a change in quadrature current has greater effect on the direct current waveform depicted in Figure 15, if compared to the result for the motor in the second link. Since the direct current is driven to a constant value for low speeds, it leads to a major increase in the load, and consequently in the quadrature current. On the other hand, the direct current in the third link is not significantly affected, as show in Figure 18. Finally, it is important to state that all currents varied around the sliding manifold $s=0$ with the chattering controlled by the terms $\left(q_{\mathrm{i}}-\left|\mathrm{a}_{\mathrm{ij}}-\hat{\mathrm{a}}_{i j}\right|\right)$ in equation (34), as in Figures 14, 15, 17, and 18. The simulation results shown in Figures 8, 9, 10 and 11 are consequently validated, with almost the same amplitude. If compared to the same scheme using vector control to drive the induction motors [19], it becomes evident that the proposed SMC approach has provided improved performance.

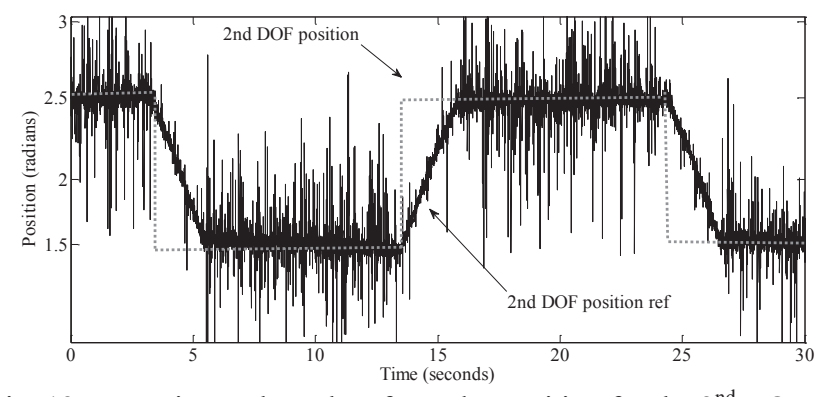

Fig. 13. Experimental results of angular position for the $2^{\text {nd }} D O F$.

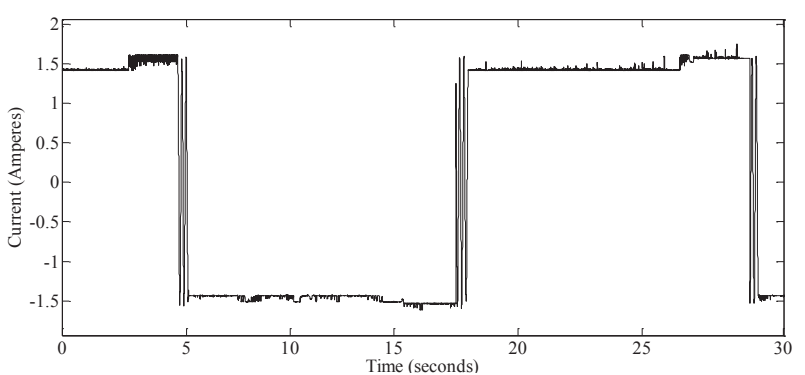

Fig. 14. Experimental results of induction motor quadrature current for the $2^{\text {nd }}$ DOF.

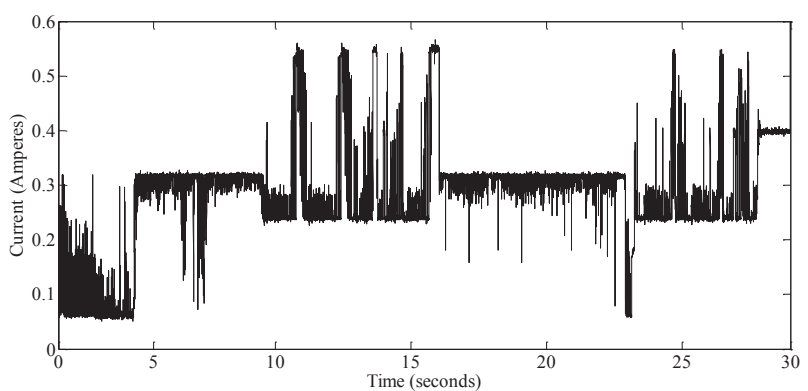

Fig. 15. Experimental results of induction motor direct current for the $2^{\text {nd }} \mathrm{DOF}$

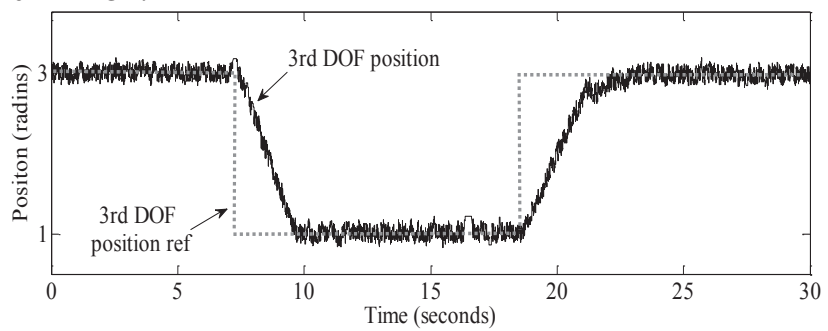

Fig. 16. Experimental results of angular position of $3^{\text {rd }}$ DOF.

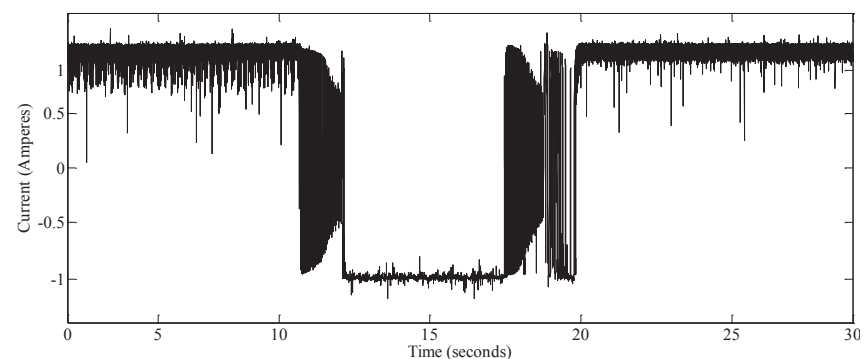

Fig. 17. Experimental results of induction motor quadrature current for the $3^{\text {rd }} \mathrm{DOF}$. 


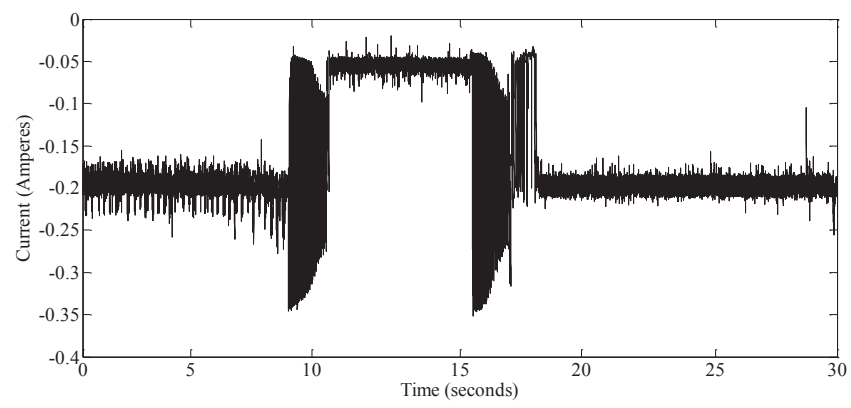

Fig. 18. Experimental results of induction motor direct current for $3^{\text {rd }} \mathrm{DOF}$.

\section{CONCLUSION}

This paper has successfully demonstrated the application of a sliding mode current control scheme for an elbow manipulator joint control based on the nonlinear model of induction motors. Parameters for the position and speed controllers such as the manipulator's mechanical coupling are taken into account in the SMC control, offering an intuitive design and implementation with low complexity for practical interest. It allows tracking the desired trajectory reference for the motor link coordinates under the assumption that manipulator's mechanical coupling can be modeled and interpreted as a load on the induction motor shaft, thus having direct influence on both direct and quadrature currents. This approach has provided improved results considering the position tracking reference, if compared to the vector control scheme, which has not been implemented considering the mechanical coupling. The SMC algorithm was implemented on a DSP due to low computational effort, enabling its application in industrial environment. The results give low error at steady-state for the manipulator position. The provided simulation and experimental results on the implemented manipulator have then validated the proposed control system.

\section{REFERENCES}

[1] P. Jussi, "Induction Motor Versus Permanent Magnet Synchronous Motor in Motion Control Applications: A Comparative Study". D.Sc. Thesis. Department of Electrical Engineering. University of Lappeenranta, Lappeenranta, Finland, 2006.

[2] D. W. Novotny, T. A Lipo, Vector Control and Dynamics of AC Drives. Oxford Science Publications, $1^{\text {st }}$ Edition, 1997.

[3] A. M. Trzynadlowski, The Field Orientation Principle in Control of Induction Motors. Springer Publishing, $1^{\text {st }}$ Edition ,1982.

[4] F. Blaschke, The Principle of Field Orientation - the Basis for the Transvector Control of Three-Phase Machines. Siemens Zeitschrift, Vol. 45, No. 10, pp. 757760, 1971.

[5] D. Casadei, F. Profumo, G. Serra, A. Tani, "FOC and DTC: Two Viable Schemes for Induction Motor Torque Control." IEEE Transactions on Power Electronics, vol. $17, \mathrm{n}^{\circ} .5$, pp. 779-787, 2002.
[6] H.T Camara, E.G. Carati, H.L. Hey, H. Pinheiro, J.R. Pinheiro, H.A. Grundling,"Speed and Position Servo for Induction Motor using Robust Model Reference Adaptive Control" . IECON 28th Annual Conference of the Industrial Electronics Society, vol. 2, pp. 1721 - 1727 March 2003.

[7] M. W. Spong, M. Vidyasagar, Robot, Dynamics and Control. Ed. Wiley \& Sons (Asia), $1^{\text {st }}$ Edition, 2004.

[8] S. M. Gadoue, D. Giaouris, J. W. Finch, "Sensorless Control of Induction Motor Drives at Very Low and Zero Speeds Using Neutral Network Flux Observers", IEEE Transactions on Industrial Electronics, vol. 56, issue 8, pp. 3029-3039, 2009.

[9] K. Szabat, T. Orlowska-Kowalska, M. Dybkowski, "Indirect Adaptive Control of Induction Motor Drive System with an Elastic Coupling.", IEEE Proceedings in Electronic Industrial Electronics, vol. 56, issue 10, pp. 4038-4042, 2009.

[10] L. G. Shiau, J. L. Lin, "Stability of Sliding-mode Current Control for High Performance Induction Motor Position Drives." IEEE Proceedings in Electronic Power Applications, vol. 148, no. 1, pp. 69-75, 2001.

[11] C. C. Chan, H. Q. Wang, "New Scheme of Sliding-Mode Control for High Performance Induction Motor Drives." IEEE Proceedings in Electric Power Applications, vol. 143, n³, pp. 177-185, 1996.

[12] E. C. Diniz, A. B. S. Júnior, D. A. Honório, O. M. Almeida, L. H. S. C. Barreto, "Comparison Between Sliding Mode Control and Vector Control for a DSPBased Position Control Applied to Squirrel-Cage Induction Motor", in Proc. of INDUSCON, vol. 01, pp 553-558, 2010.

[13] M. Osama, O. Abdul-Azim, "Implementation and Performance Analysis of An Elevator Electric Motor Drive System". 12th International Middle-East Power System Conference, vol. 05, pp 123-128, 2008.

[14] S.-H. Huh and Z. Bien, "Robust Sliding mode Control of a Robot Manipulator Based on Variable Structure-Model Reference Adaptive Control Approach", IET Control Theory Appl., vol. 1, n5, pp. 1355-1363, 2007.

[15] P. Tomei, C. M. Verrelli, M. Montanari, A. Tilli, "Robust Output Feedback Learning Control for Induction Motor Servo Drives," International Journal of Robust and Nonlinear Control., vol. 19, issue 15, pp. 1745-1759, 2009.

[16] Faa-Jeng Lin, Po-Kai Huang, W.-D. Chou, "RecurrentFuzzy-Neural-Network-Controlled Linear Induction Motor Servo Drive Using Genetic Algorithms". IEEE Transactions on Industrial Electronics, vol. 54, issue 3, pp. 1449-1461, 2007.

[17] R. Kumar, R. A. Gupta, S.V. Bhangale, "Vector Control Techniques for Induction Motor Drive: A Review." International Journal of Automation and Control, vol. 3, no. 4, pp. 284-306, 2009.

[18] K. J. Aström, T. H. Lee, K. K. Tan, K. H. Johansson, "Recent Advances in Relay Feedback Methods-A Survey." IEEE International Conference on Systems, Man and Cybernetics, 1995. Intelligent Systems for the 21st Century, pp. 2616-2621, vol.3, 1995. 
[19] E. C. Diniz, A. B. S. Júnior, D. A. Honório, O. M. Almeida, L. H. S. C. Barreto, "Simplified Approach for Modelling and Control a 3-DOF RRR type Robotic Manipulator Using Squirrel-Cage Induction Motors", in Proc. INDUSCON, 2010.

[20] J. Holtz, "Pulse Width Modulation for Electronic Power Conversion", Proc. IEEE, vol. 82, pp. 1194-1214, 1994.

[21] B. K, Bose, Modern Power Electronics and AC Drives. Prentice-Hall, $1^{\text {st }}$ Edition, 2001.

[22] W. Gao, J. C. Hung, "Variable Structure Control Of Nonlinear Systems: A New Approach", IEEE Transactions on Industrial Electronics, vol. 49, $\mathrm{n}^{\circ} .1, \mathrm{pp}$. 45-55, 1993.

\section{BIOGRAPHIES}

Eber de Castro Diniz was born in Salvador, Brazil, in 1977. He received the B.Sc. degree in electrical engineering from the Federal University of Ceará, Fortaleza, Brazil, in 2003 and the B.Sc. degree in electrical engineering in 2006 from the same university. He currently serves as assistant professor at the Federal University of Ceará, Sobral, Brazil at the Department of Electrical Engineering. His areas of interest are Predictive Control, Optimal Control, Robust Control, Electrical Machines, Power Electronics, Embedded Systems, Control applied to Power Generation, and Vector Control.

Antonio Barbosa de Souza Júnior was born in Fortaleza in 1984. He received the B.Sc. degree in Control and Automation Engineering from the University of Fortaleza, Fortaleza, Brazil in 2007, and also the M.Sc. degree in Electrical Engineering from the Federal University of Ceará, Fortaleza, Brazil in 2010. Currently he is PhD student at the Federal University of Ceará. His interest areas are Electrical Machines Drives, Power Electronics, Vector Control, and Robotics.

Dalton de Araújo Honório was born in Fortaleza, Brazil, in 1988. He received the B.Sc. degree in Electrical Engineering from the Federal University of Ceará, Fortaleza, Brazil, in 2010. He is currently pursuing the M.Sc. degree in Electrical Engineering at the same university and, acting as a researcher for $\mathrm{CNPq}$ at the same institution, working on the development of $\mathrm{AC}$ machine drive for robotic applications.

Luiz Henrique Silva Colado Barreto was born in Navirai, Brazil. He received the B.S. degree in Electrical Engineering from the Federal University of Mato Grosso, Cuiabá, Brazil, in 1997, and the M.S. and Ph.D. degrees from the Federal University of Uberlandia, Uberlandia, Brazil, in 1999 and 2003, respectively. Since June 2003, he has been with the Department of Electrical Engineering, Federal University of Ceará, Fortaleza, Brazil, where he is currently a Professor with the Department of Electrical Engineering. His research interests include high-frequency power conversion, modeling and control of converters, power factor correction circuits, new converter topologies, uninterruptible power system systems, and fuel cells.
Laurinda Lúcia Nogueira dos Reis received the B.Sc. degree in Electrical Engineering from the Federal University of Ceará, Fortaleza, Brazil in 1979, and the M.Sc. degree in Electrical Engineering from the Federal University of Paraíba, Campina Grande, Brazil in 1984, respectively. She obtained the Ph.D. degree degree in Electrical Engineering from the Federal University of Santa Catarina, Florianópolis, Brazil in 2008. She has been a professor with the Federal University of Ceará, Fortaleza, Brazil since 1979. Her research interest areas are electric machinery, electric machine drives, advanced techniques for electromechanical systems, and nonlinear systems. 